\title{
Acute Renal Failure in Systemic Lupus Erythematosus (SLE): An Unusual Case Report
}

\section{Kaaroud H*, Ben Kaab B, Boubaker K, Elloumi Z, BelKadhi Y, Hajji N, Ben Maiz H and Kheder A}

Department of Internal Medicine, Charles Nicolle Hospital, Tunis-Tunisia

\begin{abstract}
Retroperitoneal fibrosis is most often idiopathic; however it may be associated with several conditions such as malignancies, drugs and systemic diseases. We describe a case of retroperitoneal fibrosis and renal veins thrombosis with acute renal failure in a 25 -year old SEL woman.
\end{abstract}

Keywords: Retroperitoneal fibrosis; Systemic erythematosus lupus; Acute renal failure

\section{Introduction}

In patient with SLE retroperitoneal fibrosis (RPF) is a rare cause of acute renal failure [1-6].

Thrombosis of the inferior vena cava and its major branches resulting from compression by the fibrous mass is not a rare complication of RPF [7].

We report a female patient with SLE who presented with obstructive nephropathy and bilateral renal vein thrombosis due to RPF.

\section{Case Report}

A 25- year old woman presented with fever, weight loss, abdominal and bilateral renal pain, oliguria and macroscopic hematuria. The patient had also been suffering from photosensitivity and recurrent arthralgia. She had a family history of SLE; her mother was suffering from SLE without nephropathy.

Physical examination revealed an ill-looking pale patient, with a temperature of $38^{\circ} \mathrm{C}$, blood pressure of $100 / 60 \mathrm{mmHg}$. Cardiac and pulmonary examination was unremarkable. There was no hepatosplenomegaly.

Laboratory investigation revealed hemoglobin of $7 \mathrm{~g} / \mathrm{dl}$; white blood cell count of $3310 / \mathrm{mm}$; lymphocytes of $430 / \mathrm{mm}$; platelet count of 200000/mm, ESR of $107 \mathrm{~mm} /$ hour; blood urea of $30 \mathrm{mmol} / \mathrm{l}$; serum creatinine of $600 \mu \mathrm{mol} / \mathrm{l}$; Proteinemia of $75 \mathrm{~g} / \mathrm{l}$, Albuminemia of $35 \mathrm{~g}$.

Serologic tests showed low serum complement C3, C4 levels, positive DNA antibody, positive antiphospholipide antibody and positive antinuclear antibody.

Ultrasound of abdomen with Doppler ultrasound renal studies revealed high sized kidneys with bilateral hydronephrosis and bilateral renal vein thrombosis. Computer-assisted tomography of the abdomen and pelvis showed extensive soft tissue infiltration concentrically around the aorta, inferior vena cava and both ureters. No adenopathy and tumor was noted.

After insertion of double J- shaped transurethral catheters one day after admission; daily administration of $1 \mathrm{mg} / \mathrm{kg} / \mathrm{day}$ of prednisolone and anticoagulants the patient's urine output improved over a period of 15 days during which she required 4 hemodialysis sessions and serum creatinine normalized in 5 weeks. We started hemodialysis at first because of oliguria and after because of increased rate of urea under corticosteroids.

After the removal of ureteral catheters, the macroscopic hematuria disappeared and renal biopsy was not performed since there were no urinary abnormalities.

A CT-scan performed 6 months later confirmed the resolution of both RPF and renal vein thrombosis.

\section{Discussion}

RPF is a chronic, non specific inflammation of retroperitoneum. About $65 \%$ of the cases were idiopathic. The mechanism of the disorder is not clearly defined. Inflammation and secondary fibrosis are the main suspected mechanisms against unknown factor possibly related to atherosclerosis. One-third of the cases are secondary to malignancy, medication (methysergide, hydralazine, beta blockers), aortic aneurysm, certain infections or auto immune diseases [8].

The occurrence of RPF in SLE is increasingly reported with hypothesis that this association is not fortuitous, but reflects a common immunological mechanism [6].

In our patients with lupus, acute renal failure is usually related to severe lupus nephritis. Among 211 patients hospitalized in our department for lupus nephritis; acute renal failure was noted in $51.6 \%$ of cases related to class III or IV lupus nephritis [9].

Although the patient had some typical features of RPF, fever, weight loss, abdominal pain and anuria, the diagnosis was not considered on clinical data but it was established after radiological exploration.

Since these clinical manifestations of RPF are frequent in severe forms of lupus nephritis, we assumed that the patient had extra capillary glomerulonephritis.

Thrombophlebitis of the inferior vena cava due to fibrosis compression is a less common clinical manifestation but the bilateral renal vein thrombosis is due probably to the phospholipids syndrome in our case which has never been reported.

In our experience this is the first case of acute renal failure related

*Corresponding author: Hayet Kaaroud, Department of Internal Medicine Charles Nicolle Hospital, Boulevard 9 Avril, 1006 Bab Souika, Tunis-Tunisia, Tel. 0021698430195; Fax: 0021671562670; E-mail: hayet.kaarout@rns.tn

Received February 28, 2012; Accepted March 20, 2012; Published March 26 2012

Citation: Kaaroud H, Ben Kaab B, Boubaker K, Elloumi Z, BelKadhi Y, et al. (2012) Acute Renal Failure in Systemic Lupus Erythematosus (SLE): An Unusual Case Report. J Clinic Case Reports 2:117. doi:10.4172/2165-7920.1000117

Copyright: (c) 2012 Kaaroud H, et al. This is an open-access article distributed under the terms of the Creative Commons Attribution License, which permits unrestricted use, distribution, and reproduction in any medium, provided the original author and source are credited. 
Citation: Kaaroud H, Ben Kaab B, Boubaker K, Elloumi Z, BelKadhi Y, et al. (2012) Acute Renal Failure in Systemic Lupus Erythematosus (SLE): An Unusual Case Report. J Clinic Case Reports 2:117. doi:10.4172/2165-7920.1000117

to obstructive nephropathy and bilateral renal vein thrombosis due to RPF in SLE. To our knowledge there are no similar cases previously reported.

RPF is most common in individuals from 50 to 70 years of age. Men are more likely to develop the condition than women.

The young age of our patient is explained by the fact that SLE is usually a disease that most often strikes reproductive-aged women.

Often lupus and RPF occurred in the same time; however in some cases RPF preceded lupus presentation.

There is probably a genetic predisposition of SLE and FR association. The HLA antigens found in some cases were A2, AW33, B8, DR3, and DR6.

The treatment of RPF depends on the etiology. Optimal care requires an integrated approach of surgical and nonsurgical therapies. The aims of management are to preserve renal function, to prevent other organ involvement and to relieve symptoms.

Steroids are normally used for one year although other options: Eg. immunosuppressive, tamoxifen are available. Patients are followed regularly and medications adjusted based on follow-up imaging studies and blood tests (sedimentation rate and C-reactive protein).

If the RPF is due to a secondary cause, treatment is aimed at the underlying etiology.

Since the underlying disease in our patient is SEL; she was treated by corticoids with a favorable outcome. Because of the antiphospholipid syndrome it is necessary to maintain this patient on anticoagulant therapy to prevent renal vein thrombosis.

\section{Conclusion}

During SLE; without radiological study it's difficult to relate acute renal failure to RPF because the clinical manifestations of both diseases are similar. Management of RPF in SLE is the same in idiopathic RPF. However we believe that a regular monitoring is needed to prevent the recurrence of RPF that occurs obviously during relapse of SLE.

\section{References}

1. Lipman RL, Johnson B, Berg G, Shapiro AP (1966) Idiopathic retroperitoneal fibrosis and probable systemic lupus erythematosus. JAMA 196: 1022-1024.

2. Lloyd DD, Balfe JW, Barkin M, Gelfand EW (1974) Systemic lupus erythematosus with signs of retroperitoneal fibrosis. J Pediatr 85: 224-226.

3. Lichon FS, Sequeira W, Pilloff A, Skosey JL (1984) Retroperitoneal fibrosis associated with systemic lupus erythematosus: a case report and brief review. J Rheumatol 11: 373-374.

4. Uchino K, Hasegawa O, Matsumaru K, Ochiai H, Yakuwa H, et al. (1986) A case of retroperitoneal fibrosis associated with systemic lupus erythematosus. Nihon Naika Gakkai Zasshi 75: 666-669.

5. Okada H, Takahira S, Sugahara S, Nakamoto H, Suzuki H (1999) Retroperitoneal fibrosis and systemic lupus erythematosus. Nephrol Dial Transplant 14: 1300-1302.

6. Granata A, Stella M, Santoro D, Castellino S (2006) Acute renal failure secondary to retroperitoneal fibrosis as first manifestation of lupus nephritis. G Ital Nefrol 23: 86-89.

7. Bashour B (1993) Systemic lupus erythematosus with retroperitoneal fibrosis and thrombosis of the interior vena cava. South Med J 86: 1309-1310.

8. Demko TM, Diamond JR, Groff J (1997) Obstructive Nephropathy as a result of retroperitoneal fibrosis: A review of its pathogenesis and associations. J Am Soc Nephrol 8: 684-688.

9. Beji S, Kaaroud H, Ben Moussa F, Aberrahim E, Goucha R, et al. (2005) Lupus nephritis: 211cases. Rev Med Interne 26: 8-12. 